\title{
PENGARUH KUALITAS PELAYANAN KESEHATAN TERHADAP MINAT PASIEN DALAM MEMANFAATKAN KEMBALI JASA PELAYANAN RAWAT JALAN DI PUSKESMAS WARA UTARA KECAMATAN BARA KOTA PALOPO TAHUN 2016
}

\author{
The Influence of Health Service Quality to The Patient Interest In Using \\ The Outpatient Service
}

\author{
Martini Baharuddin, ${ }^{1}$ Nur Asphina R. Djano, ${ }^{2}$ I Wayan Djuliarsa, ${ }^{3}$ \\ ${ }^{1}$ Program Studi Kesehatan Masyarakat STIKES Mega Buana Palopo (E-mail: jc_thini@yahoo.com) \\ ${ }^{23}$ Dosen STIKES Mega Buana Palopo (E-mail: phinakeng2@yahoo.com)
}

\begin{abstract}
ABSTRAK
Puskesmas adalah fasilitas pelayanan kesehatan yang menyelenggarakan upaya kesehatan masyarakat dan upaya kesehatan perorangan tingkat pertama. Penelitian ini bertujuan untuk mengetahui Pengaruh kualitas pelayanan kesehatan terhadap minat pasien dalam memanfaatkan kembali jasa pelayanan rawat jalan di Puskesmas Wara Utara Kecamatan Bara Kota Palopo.

Penelitian ini adalah survey dengan rancangan cross sectional study, populasi dalam penelitian ini adalah pasien rawat jalan yang berkunjung di Puskesmas Wara Utara Kecamatan Bara Kota Palopo 97 responden. Pengumpulan data menggunakan kuesioner. Data yang dikumpulkan kemudian diolah dan dianalisis menggunakan computer program Microsoft excel dan program statistik (SPSS) Versi 20.

Analisis univariat mencari distribusi frekuensi, analisis bivariat didapatkan ada pengaruh kebijakan pelayanan terhadap minat pasien dalam memanfaatkan kembali jasa pelayanan $(\rho=0,005)$, terdapat pengaruh pelayanan Dokter terhadap minat pasien dalam memanfaatkan kembali jasa pelayanan ( $\rho$ $=0,002)$, terdapat pengaruh ketepatan waktu pelayanan terhadap minat pasien dalam memanfaatkan kembali jasa pelayanan $(\rho=0,004)$.

Terdapat pengaruh kebijakan pelayanan kesehatan, pelayanan dokter dan ketepatan waktu pelayanan terhadap minat pasien dalam memanfaatkan kembali jasa pelayanan di Puskesmas Wara Utara Kecamatan Bara Kota Palopo Tahun 2016.
\end{abstract}

Kata Kunci: Minat Memanfaatkan Kembali Jasa Pelayanan Kesehatan, Kebijakan Pelayanan Kesehatan, Pelayanan Dokter, Ketepatan Waktu Pelayanan

\begin{abstract}
Public health center is a health service facility hosting the efforts of public and individual health effort first level. This research is aimed to find to know the influence of the health services quality against patients interest in using the outpatient services in the service at the Public Health Center Wara Utara Kecamatan Bara Palopo.This research is a survey research by using cross sectional study design, population in this research is all the outpatients who visited Public Health Center Wara Utara Kecamatan Bara Palopo and it was got 97 respondents based on inclusion criteria. The data was collected by using questionnaires. The data that has been collected, later processed and analyzed by using the computer program Microsoft Excel and the statistical program (SPSS) 20 Version. The result showed there is univariat analysis search the frequency distribution, from bivariat analysis it was obtained that there is an influence of the service policy to the patients interests in utilizing the service $(\rho=0,002)$, there is an influence of the doctor service to the patients interests in utilizing the service ( $\rho$
\end{abstract}


$=0,001)$, the is an influence of the service time accuracy to the patients interest in utilizing the service $(\rho=0,000)$. The Conclution there is an influence of health service policy, the doctors service and the service time accuracy to the patient interest in utilizing the service at the Public Health Center Wara Utara Kecamatan Bara Palopo, 2016.

\section{Keywords: Interest In Utilizing The Health Service, Service Policy, Doctor Service, Service Time Accuracy}

\section{PENDAHULUAN}

Minat memanfaatkan kembali pelayanan kesehatan didefinisikan sebagai keinginan pasien untuk menggunakan ulang atau tidak pelayanan, yang merupakan bagian dari perilaku purna pembelian setelah membeli produk, konsumen akan mengalami level kepuasan atau ketidakpuasan. Begitupun dengan instansi pelayanan kesehatan seperti puskesmas jika pelayanan yang mereka berikan tidak berkualitas maka kepuasan seorang pasien tidak akan terpenuhi secara prima sebaliknya jika pelayanan yang diberikan berkualitas maka kemungkinan pasien akan terus kembali menggunakan pelayanan tersebut. ${ }^{1}$

Faktor yang mempengaruhi minat pasien untuk memanfaatkan kembali jasa pelayanan kesehatan yaitu: kebijakan pelayanan kesehatan, pelayanan dokter, ketepatan waktu pelayanan. $^{2}$

Suatu penelitian yang dilakukan untuk mengetahui mengapa pasien pelanggan tidak kembali lagi memanfaatkan pelayanan ditemukan kenyataan sebagai berikut: 3\% karena pindah tempat tinggal, 5\% karena menemukan persahabatan dengan perusahaan lain, 9\% karena bujukan pesaing, 14\% karena tidak puas dengan mutu pelayanan dan $68 \%$ karena sikap masa bodoh atau ketidak pedulian perusahaan. $^{3}$

Kualitas merupakan suatu kondisi dinamis yang berhubungan dengan produk, jasa, manusia, proses, dan lingkungan yang memenuhi atau melebihi harapan konsumen. ${ }^{4}$

Dari penelitian-penelitian sebelumnya tentang kualitas jasa pelayanan telah banyak menjelaskan bahwa terdapat beberapa faktor penentu, antara lain yaitu tangibility atau aspek yang terlihat secara fisik misalnya peralatan dan personel, reliability atau kemampuan untuk memiliki performa yang bisa diandalkan dan akurat, responsiveness atau kemauan untuk merespon keinginan atau kebutuhan akan bantuan dari pelanggan, serta pelayanan yang cepat, assurance atau kemauan para personel untuk menimbulkan rasa percaya dan aman kepada pelanggan, emphaty atau kemauan personel untuk peduli dan memperhatikan setiap pelanggan. ${ }^{5}$

Laporan tahunan kunjungan pasien di Puskesmas Wara Utara Kecamatan Bara Kota Palopo pada tahun 2013 sebanyak 11.707, tahun 2014 sebanyak 11.120, dan tahun 2015 sebanyak 9.786 menunjukkan bahwa selama tiga tahun terakhir, jumlah kunjungan mengalami penurunan. ${ }^{6}$

Tujuan Penelitian ini yaitu Untuk Mengetahui pengaruh kualitas pelayanan kesehatan terhadap minat pasien dalam memanfaatkan kembali jasa pelayanan rawat jalan di Puskesmas Wara Utara Kecamatan Bara Kota Palopo Tahun 2016.

\section{METODE PENELITIAN}

Penelitian ini menggunakan survey dengan rancangan cross sectional study. Penelitian dilaksanakan di Puskesmas Wara Utara, Kelurahan Rampoang, Kecamatan Bara Kota Palopo Tahun $2016 .{ }^{7}$

Populasi dalam penelitian ini yaitu sebanyak 2.904 pasien. Sampel penelitian sebanyak 97 dengan menggunakan teknik pengambilan sampel dipilih berdasarkan metode simple random sampling.

Tehnik pengumpulan data ada dua yaitu data primer dan data sekunder. Data primer diperoleh melalui wawancara langsung terhadap responden menggunakan kuesioner. 
Metode analisa data dilakukan dengan analisis kuantitatif, yang terdiri dari analisis univariat (disajikan dalam bentuk distribusi frekuensi), analisis bivariat dengan menggunakan uji chi square dengan bantuan program SPSS versi 20.

\section{HASIL}

Tabel 1 menunjukkan bahwa dari 97 responden yang diteliti, di mana jumlah responden yang berminat sebanyak 77 responden $(79.4 \%)$ sedangkan yang tidak berminat yaitu sebanyak 20 responden (20.6\%). Dari 97 responden yang diteliti, di mana jumlah responden yang menilai kebijakan pelayanan baik sebanyak 77 responden $(79.4 \%)$ dan yang menilai kurang baik sebanyak 20 responden (20.6\%). Dari 97 responden yang diteliti, di mana jumlah responden yang menilai pelayanan dokter baik sebanyak 72 responden (74.2\%) dan yang menilai kurang baik sebanyak 25 responden (25.8\%). Dari 97 responden yang diteliti, di mana penilaian terhadap ketepatan waktu pelayanan responden menilai baik sebanyak 90 responden $(92.8 \%)$ dan yang menilai kurang baik sebanyak 7 responden $(7.2 \%)$.

Tabel 2 menunjukkan bahwa dari 77 responden yang menyatakan kebijakan pelayanan kesehatan puskesmas baik, persentase responden yang berminat memanfaatkan kembali pelayanan kesehatan sebanyak 66 responden (85.7\%). Sedangkan dari 20 responden yang menyatakan kebijakan pelayanan kesehatan kurang baik, dimana yang berminat memanfaatkan kembali pelayanan kesehatan sebanyak 11 responden (55.0\%). Hasil uji fisher exact menunjukkan bahwa nilai $\rho=0,005$ karena nilai $\rho \leq \alpha=0,05$, maka H0 ditolak dan Ha diterima.

Tabel 3 menunjukkan bahwa dari 72 responden yang menyatakan pelayanan dokter baik, persentase responden yang berminat memanfaatkan kembali pelayanan kesehatan sebanyak 63 responden (87.5\%). Sedangkan dari 25 responden yang menyatakan pelayanan dokter kurang baik, dimana yang berminat memanfaatkan kembali pelayanan kesehatan sebanyak 14 responden (56.0\%). Hasil uji chi square menunjukkan bahwa nilai $(\rho=0,002$, karena nilai $\rho \leq \alpha=0,05$, maka H0 ditolak dan Ha diterima.

Tabel 4 menunjukkan bahwa dari 90 responden yang menyatakan ketepatan waktu pelayanan puskesmas baik, persentase responden yang berminat memanfaatkan kembali pelayanan kesehatan sebanyak 75 responden (83.3\%). Sedangkan dari 7 responden yang menyatakan ketepatan waktu pelayanan puskesmas kurang baik, persentase responden yang berminat memanfaatkan kembali pelayanan kesehatan sebanyak 2 responden (28.6\%). Hasil uji fisher exact menunjukkan bahwa nilai $\rho=0,004$, karena nilai $\rho \leq \alpha=0,05$ maka H0 ditolak dan Ha diterima. 
Distribusi Responden Berdasarkan Minat Memanfaatkan Kembali, Kebijakan Pelayanan Kesehatan,

Pelayanan Dokter, Ketepatan Waktu Pelayanan di Puskesmas Wara Utara Kecamatan Bara Kota

Palopo Tahun 2016

\begin{tabular}{ccc}
\hline Variabel & \multicolumn{2}{c}{ Jumlah } \\
\cline { 2 - 3 } & n & \% \\
\hline Minat Memanfaatkan Kembali & 77 & 79.4 \\
Berminat & 20 & 20.6 \\
Tidak Berminat & & 79.4 \\
Kebijakan Pelayanan Kesehatan & 77 & 20.6 \\
Baik & 20 & 74.2 \\
Kurang Baik & & 25.8 \\
Pelayanan Dokter & 72 & \\
Baik & 25 & 92.8 \\
Kurang Baik & & 7.2 \\
Ketepatan Waktu Pelayanan & 90 & \\
Baik & 7 &
\end{tabular}

Sumber: Data Primer, 2016

Tabel 2

Pengaruh Kebijakan Pelayanan Kesehatan Terhadap Minat Memanfaatkan Kembali jasa pelayanan Rawat Jalan Di Puskesmas Wara Utara Kota Palopo Tahun 2016

\begin{tabular}{|c|c|c|c|c|c|c|c|}
\hline \multirow{3}{*}{ Kebijakan Pelayanan Kesehatan } & \multicolumn{4}{|c|}{$\begin{array}{l}\text { Minat Memanfaatkan } \\
\text { Kembali }\end{array}$} & \multirow{2}{*}{\multicolumn{2}{|c|}{ Total }} & \multirow{2}{*}{$\boldsymbol{\rho}$} \\
\hline & \multicolumn{2}{|c|}{ Berminat } & \multicolumn{2}{|c|}{$\begin{array}{c}\text { Tidak } \\
\text { Berminat }\end{array}$} & & & \\
\hline & $\mathbf{n}$ & $\%$ & $\mathbf{n}$ & $\%$ & $\mathbf{N}$ & $\%$ & \\
\hline Baik & 66 & 85.7 & 11 & 14.3 & 77 & 100.0 & 0.005 \\
\hline Kurang baik & 11 & 55.0 & 9 & 45.0 & 20 & 100.0 & \\
\hline
\end{tabular}

Tabel 3 
Pengaruh Pelayanan Dokter Kesehatan Terhadap Minat Memanfaatkan Kembali Jasa

Pelayanan Rawat Jalan Di Puskesmas Wara Utara Kota Palopo Tahun 2016

\begin{tabular}{|c|c|c|c|c|c|c|c|}
\hline \multirow{3}{*}{ Pelayanan Dokter } & \multicolumn{4}{|c|}{$\begin{array}{c}\text { Minat Memanfaatkan } \\
\text { Kembali }\end{array}$} & \multirow{2}{*}{\multicolumn{2}{|c|}{ Total }} & \multirow[b]{2}{*}{$\rho$} \\
\hline & \multicolumn{2}{|c|}{ Berminat } & \multicolumn{2}{|c|}{$\begin{array}{c}\text { Tidak } \\
\text { Berminat }\end{array}$} & & & \\
\hline & $\mathbf{n}$ & $\%$ & $\mathbf{n}$ & $\%$ & $\mathbf{N}$ & $\%$ & \\
\hline Baik & 63 & 87.5 & 9 & 12.5 & 72 & 100.0 & 0.002 \\
\hline Kurang baik & 14 & 56.0 & 11 & 44.0 & 25 & 100.0 & \\
\hline
\end{tabular}

Uji Chi square

Tabel 4

Pengaruh Ketepatan Waktu Pelayanan Terhadap Minat Memanfaatkan Kembali jasa pelayanan Di Puskesmas Wara Utara Kota Palopo Tahun 2016

\begin{tabular}{|c|c|c|c|c|c|c|c|}
\hline \multirow{3}{*}{ Ketepatan Waktu Pelayanan } & \multicolumn{4}{|c|}{$\begin{array}{c}\text { Minat Memanfaatkan } \\
\text { Kembali }\end{array}$} & \multirow{2}{*}{\multicolumn{2}{|c|}{ Total }} & \multirow[b]{2}{*}{$\rho$} \\
\hline & \multicolumn{2}{|c|}{ Berminat } & \multicolumn{2}{|c|}{$\begin{array}{c}\text { Tidak } \\
\text { Berminat }\end{array}$} & & & \\
\hline & $\mathbf{n}$ & $\%$ & $\mathbf{n}$ & $\%$ & $\mathbf{N}$ & $\%$ & \\
\hline Baik & 75 & 83.3 & 15 & 16.7 & 90 & 100.0 & 0.004 \\
\hline Kurang baik & 2 & 28.6 & 5 & 71.4 & 7 & 100.0 & \\
\hline
\end{tabular}

Uji Fisher Exact

\section{PEMBAHASAN}

Pengaruh Kebijakan Pelayanan Kesehatan terhadap Minat Memanfaatkan Kembali Jasa Pelayanan Kesehatan

Berdasarkan tabel 2 hasil uji hipotesis dengan menggunakan statistik menunjukkan nilai $\rho=0,005$ atau $\rho=\alpha<0,05$ artinya $\mathrm{H} 0$ ditolak dan Ha diterima sehingga dapat dikatakan bahwa ada pengaruh antara kebijakan pelayanan kesehatan terhadap minat pasien dalam memanfaatkan kembali pelayanan kesehatan di Puskesmas Wara Utara Kota Palopo tahun 2016. Hasil penelitian ini menunjukkan bahwa kebijakan pelayanan kesehatan sangat dibutuhkan karena keberadaannya memiliki pengaruh terhadap masyarakat untuk memanfaatkan kembali jasa pelayanan kesehatan. Membicarakan tentang kebijakan pelayanan kesehatan berarti membicarakan semua kebijakan yang mempengaruhi kehidupan masyarakat, termasuk bidang kesehatan yang tidak luput dari kehidupan masyarakat. Faktor yang mendukung baiknya kebijakan pelayanan kesehatan adalah ketika masyarakat tidak merasakan kesulitan pada saat memanfaatkan pelayanan yang ada di

Puskesmas maupun instansi lainnya. Dimana sekarang ini banyak dijumpai kejanggalan-keganjalan dalam pelayanan kesehatan.

Penelitian ini sejalan dengan penelitian Hari Kusnanto et al, 2013 yang menyatakan bahwa kebijakan pelayanan kesehatan yang dibuat oleh pemerintah sangat baik karena sangat membantu masyarakat dari sisi akses pelayanan, serta meringankan beban masyarakat apalagi masyarakat ekonomi lemah.

Penelitian ini sesuai dengan teori Roger Detels et al, 2002 yang menyatakan strategi kebijakan kesehatan merupakan kebijakan publik untuk menghimpun semua potensi guna memelihara dan meningkatkan status kesehatan masyarakat. Bahkan menurut Dawnie perlu melibatkan semua kekuatan masyarakat. Dengan demikian, tingginya taat azas dan loyalitas terhadap kebijakan kesehatan nasional merupakan efektifnya administrasi pemerintah 
untuk mengkondisikan pemerintahan daerah guna menghimpun semua potensi guna memelihara dan meningkatkan status kesehatan masyarakat. $^{8}$

\section{Pengaruh Pelayanan Dokter terhadap Minat Memanfaatkan Kembali Jasa Pelayanan Kesehatan}

Berdasarkan tabel 3 hasil uji hipotesis dengan menggunakan statistik menunjukkan nilai $\rho=0,002$ atau $\rho=\alpha<0,05$ artinya $\mathrm{H} 0$ ditolak dan $\mathrm{Ha}$ diterima sehingga dapat dikatakan bahwa ada pengaruh antara pelayanan dokter terhadap minat pasien dalam memanfaatkan kembali pelayanan kesehatan di Puskesmas Wara Utara Kota Palopo tahun 2016. Hal ini menunjukkan bahwa semakin baik pelayanan dokter maka semakin besar minat pasien untuk memanfaatkan kembali pelayanan kesehatan tersebut selanjutnya.

Hasil ini sejalan dengan penelitian yang dilakukan oleh Wibawani, 2013 di Di Rumah Sakit Woodward Kota Palu dalam Karmilasari 2014, yang menyatakan bahwa ada pengaruh kompetensi teknis (pelayanan dokter) terhadap kepuasan pasien dengan nilai $(\rho=0,023)$ sehingga berminat memanfaatkan kembali pelayanan kesehatan. ${ }^{9}$

Hasil penelitian ini sejalan dengan teori yang dikemukakan Zeithaml dan Bitner, 1996 dalam Karmilasari, 2014 yang mengatakan bahwa competence menjadi salah satu faktor utama dalam menentukan baik tidaknya kualitas pelayanan. ${ }^{10}$

Menurut Hooker, 1988 dan Smith, 1970 seperti yang dikutip oleh Hakim, 2013 menyatakan bahwa sikap santun dan ramah dokter ketika berhadapan dengan pasiennya, mengerti masalah pasien, mampu menerangkan dengan kata-kata yang dimengerti oleh orang awam, mampu mendengarkan keluhan pasien serta sikap percaya diri dari petugas kesehatan lainnya ketika berhadapan dengan pasien akan memberikan kepuasan pada pasien. Hal ini menunjukkan bahwa semakin baik pelayanan Dokter maka semakin besar minat pasien untuk memanfaatkan kembali pelayanan kesehatan tersebut selanjutnya. ${ }^{11}$

\section{Pengaruh Ketepatan Waktu Pelayanan terhadap Minat Memanfaatkan Kembali Jasa Pelayanan Kesehatan}

Berdasarkan tabel 4 hasil uji hipotesis dengan menggunakan statistik menunjukkan nilai $\rho=0,004$ atau $\rho \leq \alpha=0,05$, artinya $\mathrm{H} 0$ ditolak dan Ha diterima. Hal ini berarti ada pengaruh antara ketepatan waktu pelayanan atau ketanggapan pelayanan dengan minat memanfaatkan kembali pelayanan kesehatan. Hal ini menunjukkan bahwa semakin baik ketepatan waktu pelayanan maka semakin besar minat pasien untuk memanfaatkan kembali pelayanan kesehatan tersebut selanjutnya.

Penelitian ini sejalan dengan yang dilakukan oleh Adhytyo dan Mulyaningsih, (2013) dalam Natalya, (2014) hasil menunjukkan semakin baik dan tepat dalam melakukan penanganan akan meningkatkan tingkat kepuasan sehingga pasien berminat memanfaatkan kembali pelayanan. Ketepatan waktu merupakan suatu kondisi dimana segala sesuatu dipekerjakan sesuai dengan waktunya. ${ }^{12}$

Hasil penelitian ini sesuai dengan teori yang dikemukakan Zeithaml dan Bitner, (1996) dalam Karmilasari, (2014), yang mengatakan bahwa ketepatan waktu (responsiveness) menjadi salah satu faktor utama dalam menentukan baik tidaknya kualitas pelayanan. Hasil penelitian ini sesuai dengan teori Mowen dan Minor, (2001) dalam Nurminah yusuf, (2007) mengatakan bahwa waktu dan kecepatan pelayanan merupakan salah satu atribut produk atau jasa yang dapat mempengaruhi minat beli dan kepuasan pasien. ${ }^{5}$

\section{KESIMPULAN}

Ada pengaruh antara kebijakan pelayanan kesehatan terhadap minat pasien dalam memanfaatkan kembali jasa pelayanan dengan hasil uji fisher exact $(\rho=0,005 \leq \alpha=0,05)$. Ada pengaruh antara pelayanan Dokter terhadap minat pasien dalam memanfaatkan kembali jasa pelayanan dengan hasil uji chi square $(\rho=0,002) \leq \alpha=0,05)$. Ada pengaruh antara ketepatan waktu pelayanan terhadap minat pasien dalam memanfaatkan kembali jasa 
pelayanan dengan uji fisher exact $(\rho=0,004 \leq \alpha$ $=0,05$ ).

Adapun saran peneliti untuk pihak manajemen puskesmas sebaiknya lebih memperhatikan keberadaan petugas dalam memberikan pelayanan yang cepat, dalam hal ini dapat ditingkatkan dengan penambahan tenaga atau mengatur jadwal kerja sehingga cukup tersedia tenaga pada waktu sibuk. Khususnya pada petugas puskesmas perlu meningkatkan kedisiplinan waktu dalam memberikan pelayanan agar pasien mendapatkan pelayanan yang tepat waktu.

\section{REFERENSI}

1. Hsuan Li. Meng. The Influence of Perceived Servie Quality On Brend Image Word Of Mouth And Repurchase Intention:A Case Study Of Meng-Seng General Hospital On Touyuan, Taiwan. Journal Of Marketing.Diakses Pada Tanggal 20 Maret 2013 Dari Gsbejournal. Au. Edu/Gp/Publication2/2.pdf; 2010.

2. Priyoto.. Teori Sikap dan Perilaku Dalam Kesehatan. Yogyakarta: Nuha Medika; 2014.

3. Halimatusa'diah. Hubungan Persepsi Pasien Terhadap Mutu Pelayanan Dengan Minat Pemanfaatan Ulang Rawat Jalan Umum Di Puskesmas Ciputat Timur. Jakarta: UIN Syarif Hidatullah. ;2015.

4. Tjiptono, Fandy. Manajemen Jasa. Yogyakarta: Andi Offset; 2012.

5. Karmilasari, J. Hubungan Kualitas Pelayanan Dengan Minat Pemanfaatan Kembali Pelayanan Kesehatan Di Puskesmas Jongaya Kota Makassar. Makassar: Universitas Hasanuddin; 2014.

6. Puskesmas Wara Kota (Perumnas). Profil Kesehatan Puskesmas Wara Kota (Perumnas) Kota Palopo; 2015.

7. Prasetyo, Bambang. Metode Penelitian Kuantitaif. Jakarta: PT Grafindo Persada; 2013.

8. Engel, James F, and, Blackwell, Roger D, Perilaku Konsumen, Binarupa: Jakarta; 2002.

9. Wibawani,.Pengaruh Mutu Layanan Kesehatan Terhadap Kepuasan Pasien
Rawat Inap Di Rumah Sakit Woodward Kota Palu. Palu: Jurnal Administrasi dan Kebijakan Kesehatan (AKK). 2(3): 35-41; 2013.

10. Parasuraman, Zeithmal and Bitner Konsep dan Teknik Pengukuran Kualitas Produk Jasa, Kajian Bisnis dan Manajemen; 1996.

11. Parasuraman, Et, al. Konsep dan Teknik Pengukuran Kualitas Produk Jasa, Kajian Bisnis dan Manajemen; 1988.

12. Adhytyo, D. Mulyaningsih.. Reliabilitas Mempengaruhi Kepuasan Pasien Terhadap Pelayanan Kesehatan Di Salah Satu Puskesmas Kabupaten Ngawi. Sekolah Tinggi Ilmu Kesehatan. Surakarta; 2013. 